\title{
FAKTOR - FAKTOR YANG MEMPENGARUHI PRODUKTIVITAS TENAGA KERJA PANEN KELAPA SAWIT DI PT. PERKEBUNAN NUSANTARA VI UNIT USAHA RIMBO SATU (RIMSA)
}

\author{
Dina Ayu Setiawati, Fikriman dan Isyaturriyadhah \\ Program Studi Agribisnis Fakultas Pertanian \\ Universitas Muara Bungo \\ 2019 \\ manfikri@ymail.com, isyaturriyadhah amin@yahoo.com
}

\begin{abstract}
ABSTRAK
Penelitian dilaksanakan di PT. Perkebunan Nusantara VI Unit Usaha Rimbo Satu Kecamatan Rimbo Bujang Kabupaten Tebo Pada bulan November 2018 sampai Desember 2018. Pemilihan lokasi ini dengan pertimbangan bahwa PT. Perkebunan Nusantara VI Kabupaten Tebo memiliki dua Unit Perkebunan yaitu Unit Usaha Rimbo Satu (RIMSA) Dan Unit Usaha Rimbo Dua (RIMDU) dan PT Perkebunan Nusantara VI adalah satu-satunya perkebunan kelapa sawit milik pemerintah yang ada di Kabupaten Tebo. Penelitian ini dilakukan untuk mengetahui bagaimana tingkat produktivitas tenaga kerja panen kelapa sawit di PT. Perkebunan Nusantara VI Unit Usaha Rimbo Satu Kecamatan Rimbo Bujang Kabupaten Tebo dan mengetahui faktor-faktor yang mempengaruhi produktivitas tenaga kerja panen kelapa sawit di PT. Perkebunan Nusantara VI Unit Usaha Rimbo Satu (RIMSA) Kecamatan Rimbo Bujang Kabupaten Tebo.Untuk mengetahui tingkat produktivitas tenaga kerja panen kelapa sawit di PT. Perkebunan Nusantara VI Unit Usaha Rimbo Satu Kecamatan Rimbo Bujang Kabupaten Tebo dilakukan dengan menggunakan Skala Likert. Sedangkan untuk mengetahui faktor-faktor yang mempengaruhi produktivitas tenaga kerja panen kelapa sawit di PT. Perkebunan Nusantara VI Unit Usaha Rimbo Satu Kecamatan Rimbo Bujang Kabupaten Tebo menggunakan alat analisis Regresi Linear Berganda. Hasil penelitian menunjukkan bahwa tingkat produktivitas tenaga kerja panen kelapa sawit di PT. Perkebunan Nusantara VI Unit Usaha Rimbo Satu Kecamatan Rimbo Bujang Kabupaten Tebo tinggi. Produktivitas tenaga kerja panen kelapa sawit di PT. Perkebunan Nusantara VI Unit usaha Rimbo Satu dipengaruhi oleh beberapa variabel, hal ini dapat dilihat dari nilai $\mathrm{F}$ hitung $>\mathrm{F}$ tabel yang bahwa setidaknya beberapa variabel berpengaruh nyata pada produktivitas tenaga kerja panen kelapa sawit di PT. Perkebunan Nusantara VI Unit usaha Rimbo Satu. Secara parsial faktor premi dan faktor jumlah tanggungan memberikan pengaruh nyata terhadap produktivitas tenaga kerja panen kelapa sawit, sedangkan untuk faktor usia dan faktor pengalaman bekerja tidak berpengaruh secara nyata terhadap produktivitas tenaga kerja panen kelapa sawit di PT. Perkebunan Nusantara VI Unit Usaha Rimbo Satu Kecamatan Rimbo Bujang Kabupaten Tebo.
\end{abstract}

Kata Kunci : Tenaga Kerja, Produktivitas 


\section{PENDAHULUAN}

\section{Latar Belakang}

Di era globalisasi saat ini perusahaan dalam menghadapi tekanan-tekanan untuk berubah, mereka di tuntut untuk memberikan tanggapan agar tetap bertahan dan sukses dalam persaingan bisnis saat ini dan yang akan datang. Perseroan terbatas adalah suatu unit usaha yang didirikan sebagai suatu institusi berbadan hukum, yang mana pendirinya dilakukan oleh akte notaris. Badan hukum ini mempunyai kelebihan dibanding lainnya, seperti luasnya badan usaha yang dapat dimiliki, bebas dalam pergerakan bidang usaha dan tanggung jawab yang dimiliki terbatas hanya pada modal yang di setorkan. Perseroan terbatas merupakan badan usaha dan besarnya modal perseroan tercantum dalam anggaran dasar. Setiap organisasi di kelola dan di isi oleh manusia. Tanpa manusia organisasi itu tidak ada. tidak ada manusia yang sama persis, dan setiap orang berbeda baik secara fisik maupun psikologis. Perbedaan itu seharusnya mendapatkan perhatian sehingga setiap orang dapat memaksimalkan potensinya. Dengan demikian organisasi dapat memaksimalkan efektivitas dan demikian juga masyarakat secara keseluruhan dapat memanfaatkan Sumber Daya Manusia (SDM). Yang merupakan sumber daya yang paling vital merupakan aktivitas sentral dan strategis (Kaswan, 2012). Manajemen sumber daya manusia adalah pendayagunaan, pengembangan, penilaian, pemberian balas jasa, dan pengelolaan individu anggota organisasi atau kelompok pekerja. Manajemen sumber daya manusia juga menyangkut desain pekerjaan, perencanaan pegawai, pengelolaan karier, kompensasi, evaluasi kinerja pengembangan tim kerja, sampai dengan masa pension (Sihotang, 2007). Pertanian mempunyai konstribusi penting terhadap perekonomian di Indonesia yaitu konstribusi produk dalam sumbangannya terdapat Produk Domestik Bruto (PDB) dan sebagai sumber sektor yang paling banyak menyerap tenaga kerja. Menurut Sumarsono (2009), faktor-faktor yang mempengaruhi produktivitas tenaga kerja dalam suatu perusahaan adalah sikap mental, pendidikan, ketrampilan, manajemen, hubungan industrial pancasila, tingkat penghasilan, gizi dan kesehatan, jaminan sosial, lingkungan dan iklim kerja, sarana produksi, tekhnologi, kesempatan berprestasi. Berdasarkan latar belakang masalah di atas, maka penulis tertarik untuk melaksanakan penelitian dengan judul "Faktor-Faktor Yang Mempengaruhi Produktivitas Tenaga Kerja Panen Kelapa Sawit Di PT. Perkebunan Nusantara VI Unit Usaha Rimbo Satu (RIMSA) Kecamatan Rimbo Bujang Kabupaten Tebo"

\section{Tujuan Penelitian}

1. Untuk mengetahui tingkat produktivitas tenaga kerja panen kelapa sawit di PT. Perkebunan Nusantara VI Unit Usaha Rimbo Satu Kecamatan Rimbo Bujang Kabupaten Tebo.

2. Untuk menganalisis faktor-faktor apa saja yang mempengaruhi 
produktivitas tenaga kerja panen kelapa sawit di PT. Perkebunan Nusantara VI Unit Usaha Rimbo Satu Kecamatan Rimbo Bujang Kabupaten Tebo.

\section{METODOLOGI PENELITIAN}

Waktu Dan Tempat Penelitian

Penelitian ini di laksanakan pada bulan November sampai Desember 2018 di PT. Perkebunan Nusantara VI Unit Usaha Rimbo Satu Kecamatan Rimbo Bujang Kabupaten Tebo dengan pertimbangan bahwa PT. Perkebunan Nusantara VI Kecamatan Rimbo Bujang Kabupaten Tebo memiliki dua Unit Perkebunan yaitu Unit Usaha Rimbo Satu (RIMSA) Dan Unit Usaha Rimbo Dua (RIMDU) dan PT perkebunan Nusantara VI adalah Satu-satu nya perkebunan kelapa sawit milik pemerintah yang ada di Kabupaten Tebo. Penelitian ini di lakukan di Unit Usaha Rimbo satu (RIMSA) karena Unit Usaha Rimbo Satu (RIMSA) memiliki kebun lebih luas dengan luas perkebunan 3.729,13 Ha.

\section{Metode Penelitian Dan Pengambilan Sampel}

Penelitian dilakukan dengan menggunakan metode survei, menurut Sugiyono (2017) metode survei merupakan metode yang digunakan untuk mendapatkan data dari tempat tertentu yang alamiah (bukan buatan), tetapi peneliti melakukan perlakuan dalam pengumpulan data, misalnya dengan mengedarkan kuesioner, test, wawancara terstruktur dan sebagainya. Penelitian ini dilakukan dengan teknik wawancara langsung kepada responden berdasarkan kuesioner. Sampel menurut Sugiyono (2012) adalah sebagian dari jumlah dan karakteristik yang dimiliki oleh populasi tersebut. Penelitian ini dalam pengambilan sampelnya menggunakan rumus slovin, dengan populasi tenaga kerja panen berjumlah 181 orang di bulan september, margin dari error yang di tetapkan adalah 5\% dan di dapat jumlah sampel tenaga kerja panen sejumlah 125 orang.

\section{HASIL DAN PEMBAHASAN}

Tingkat Produktivitas Tenaga Kerja Panen Kelapa Sawit Di PT. Perkebunan Nusantara VI Unit Usaha Rimbo Satu Kecamatan Rimbo Bujang Kabupaten Tebo

Produktivitas adalah suatu pandangan bahwa kualitas kerja hari ini harus lebih baik dari kualitas kerja kemarin, dengan kata lain sikap mental untuk harus selalu melakukan perbaikan dan peningkatan dalam bekerja dan dalam penghidupan pada umumnya. Kegiatan pemanen dikebun kelapa sawit PT. Perkebunan Nusantara VI Kecamatan Rimbo Bujang Kabupaten Tebo yaitu memotong tandan matang sesuai dengan prosedur perusahaan. Di dalam memanen kelapa sawit, ada ketentuan untuk memanen kelapa sawit yaitu kriteria matang panen. Kriteria matang panen yang diberlakukan di PT. Nusantara VI yaitu jika sudah terdapat 5-10 brondolan pertandan di piringan. Kriteria matang panen itu sendiri yaitu persyaratan kondisi tandan yang telah ditetapkan untuk dapat dipanen. Kriteria ini salah satu cara untuk meningkat kan suatu produktivitas tenaga kerja pemanen.

Adapun hasil produktivitas tenaga kerja berupa skor dari angket 
kuesioner dari 125 responden dapat dihasilkan nilai Produktivitas sejumlah 3291. Dari perhitungan nilai interval bahwa untuk jumlah skor nilai sejumlah 2501 - 4000 dalam kategori tinggi dan skor 1000 - 2500 dalam kategori rendah. Dalam penelitian ini tingkat produktivitas tenaga kerja panen kelapa sawit di PT. Perkebunan Nusantara VI tinggi. Karena rata-rata pemanen kelapa sawit PT. Perkebunan
Nusantara VI sudah mampu bekerja sesuai dengan target dan standar yang telah ditetap kan oleh perusahaan, selalu meningkatkan kualitas kerjanya, mutu hasil kerja selalu memenuhi standar yang di tetapkan, pemanen juga menjaga ketepatan waktu dalam bekerja, serta memperbaiki kesalahankesalahan yang ada.

Faktor-Faktor Yang Mempengaruhi Produktivitas Tenaga Kerja Panen Kelapa Sawit Di PT. Perkebunan Nusantara VI Unit Usaha Rimbo Satu Kabupaten Tebo

Berdasarkan olah data penelitian maka persamaan regresi berganda yang diperoleh yaitu sebagai berikut:

$\mathrm{Y}=12.671+0,666 \mathrm{X}_{1}-0,251 \mathrm{X}_{2}+0,219 \mathrm{X}_{3}-0,062 \mathrm{X}_{4}$

$\underline{\text { Uji Koefisien Determinasi } \mathbf{R}^{2}}$

\begin{tabular}{lllcl}
\hline \multicolumn{5}{c}{ Model Summary $^{\mathbf{b}}$} \\
\hline Model & $\mathrm{R}$ & $\mathrm{R}$ Square & $\begin{array}{c}\text { Adjusted R } \\
\text { Square }\end{array}$ & $\begin{array}{c}\text { Std. Error of the } \\
\text { Estimate }\end{array}$ \\
\hline 1 & $.618^{\mathrm{a}}$ & .382 & .361 & 1.50773 \\
\hline
\end{tabular}

a. Predictors: (Constant), Pengalaman Bekerja, Usia, Premi, Jumlah

Tanggungan

b. Dependent Variable: Produktivitas 
Uji koefisien determinasi untuk mengetahui seberapa erat pengaruh antara variabel Independen (X1, X2, $\mathrm{X} 3$ dan $\mathrm{X} 4)$ terhadap variabel dependen (Y). berdasarkan hasil olah data diperoleh hasil uji pengaruh parsial dengan menggunakan uji t. Hasil penelitian menunjukkan bahwa produktivitas tenaga kerja panen kelapa sawit dipengaruhi oleh faktor premi dan faktor jumlah tanggungan, sedangkan untuk faktor usia dan faktor pengalaman bekerja tidak mempengaruhi secara nyata terhadap produktivitas tenaga kerja panen kelapa sawit di PT. Perkebunan Nusantara VI Kabupaten Tebo. Maka diperoleh nilai Koefisien Determinasi $\mathrm{R}^{2}$ sebesar 0,382 atau $38,2 \%$ yang menunujukkan bahwa keragaman variabel tingkat premi, usia, jumlah tanggungan dan pengalaman bekerja menentukan produktivitas panen kelapa sawit di PT. Perkebunan Kelapa Sawit sebesar 38,2\%. Sedang produktivitas panen kelapa sawit sebesar $61,8 \%$ ditentukan oleh variabel-variabel lain diluar faktor penentu yang dimasukkan dalam model. Karena nilai $\mathrm{R}$ square dibawah $5 \%$ atau cenderung mendekati 0 maka dapat disimpulkan kemampuan variabel-variabel independen dalam menjelaskan variasi variabel dependen sangat terbatas.

Tabel 1. Uji t

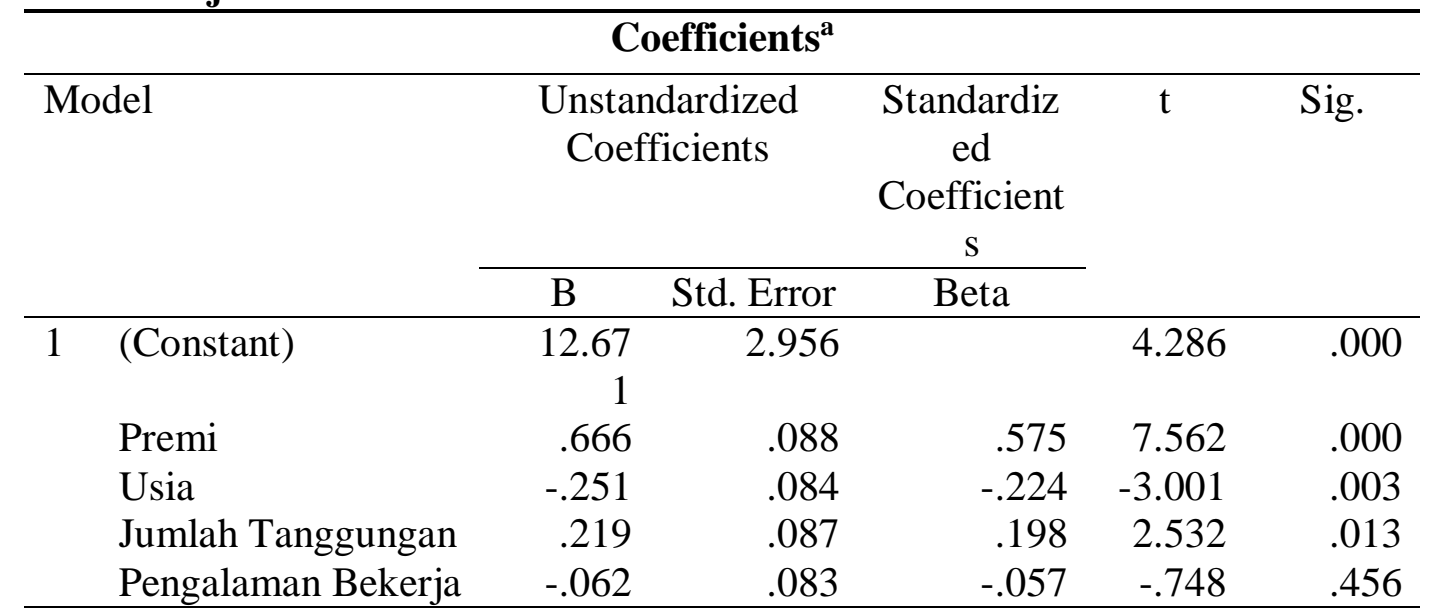

a. Dependent Variable: Produktivitas 
Berdasarkan hasil penelitian maka dapat dilihat pengaruh masing-masing variabel Independen yaitu Premi (X1), Usia (X2), Jumlah Tanggungan (X3), dan Pengalaman Bekerja (X4) terhadap variabel dependen yaitu Produktivitas (Y) dengan ketentuan sebagai berikut :

1. Jika $\mathrm{t}$ hitung $<\mathrm{t}$ tabel berarti h1 ditolak, artinya secara parsial variabel independen (premi, usia, jumlah tanggungan, pengalaman bekerja) tidak mempengaruhi Variabel dependen (Produktivitas)

2. Jika $\mathrm{t}$ hitung $\geq \mathrm{t}$ tabel berati h1 di terima, artinya secara parsial variabel independen (premi, usia, jumlah tanggungan, pengalaman bekerja) mempengaruhi variable dependen (Produktivitas) (Sudjana, 2005)

\section{Premi $\left(\mathbf{X}_{1}\right)$}

Dari hasil analisis didapat hasil nilai koefisien regresi 0,666 hal ini terlihat dari nilai $\mathrm{t}$ hitung $7.562>\mathrm{t}$ tabel 1,65. Dengan lebih besarnya nilai $t$ hitung dari nilai $t$ tabel ( $t$ hitung $>\mathrm{t}$ tabel) maka $\mathrm{H}_{1}$ diterima dan $\mathrm{Ho}$ ditolak, Artinya secara parsial premi berpengaruh sangat nyata terhadap produktivitas tenaga kerja panen di PT. Perkebunan Nusantara VI Kabupaten Tebo. Hal ini karenakan oleh pemberian premi yang sudah sesuai dengan usaha yang dikeluarkan tenaga kerja.

\section{Usia $\left(\mathbf{X}_{2}\right)$}

Koefisien regresi usia yang digunakan pada analisis yang terdapat pada tabel 8 adalah sebesar -0,251 dan nilai $\mathrm{t}$ hitung $-3.001>\mathrm{t}$ tabel 1,65, sehingga Ho ditolak dan $\mathrm{H} 1$ diterima.
Berarti bahwa usia tenaga kerja panen kelapa sawit berpengaruh secara negatif terhadap produktivitas tenaga kerja panen kelapa sawit di PT. Perkebunan Nusantara VI Kecamatan Rimbo Bujang Kabupaten Tebo. Di Negara Indonesia sendiri terdapat batasan usia untuk bekerja, di mulai dari usia 15 tahun hingga 64 tahun. Penelitian ini kalau dilihat dari lapangan faktor usia berpengaruh secara negatif. Jika diatas menunjukkan usia semakin tua semakin tidak produktif, maka dalam penelitian ini hal ini tidak sejalan karena pemanen mengatakan bahwa untuk pemanen yang sudah mempunyai keluarga atau jumlah tanggungan keluarga dapat lebih termotivasi akan pekerjaannya karena menurut mereka lebih memikirkan jumlah tanggungan yang ada dalam keluarganya.

\section{Jumlah Tanggungan $\left(\mathbf{X}_{\mathbf{3}}\right)$}

Dari hasil analisis di dapat nilai koefeisien regresi dari jumlah tanggungan sebesar 0,219 dan nilai $t$ hitung $2.532>\mathrm{t}$ tabel 1,65 sehingga Ho ditolak dan $\mathrm{H} 1$ diterima. Berarti bahwa jumlah tanggungan keluarga berpengaruh nyata pada tingkat produktivitas tenaga kerja panen kelapa sawit. Hal ini diduga disebabkan oleh jumlah keluarga yang semakin banyak maka tenaga kerja termotivasi untuk meningkat kan produktivitas nya. Menurut Hernanto (1989) bahwa petani yang mempunyai tanggungan yang lebih besar akan diburu oleh kebutuhan keluarga. Dengan demikian ia akan berusaha semaksimal mungkin untuk memenuhi kebutuhannya. 


\section{Pengalaman kerja $\left(\mathbf{X}_{4}\right)$}

Nilai koefesien regresi dari pengalam berkerja senilai $-0,062$ dan didapat nilai $\mathrm{t}$ hitung $-0,748<\mathrm{t}$ tabel 1,65 . sehingga Ho diterima dan H1 ditolak. Berarti bahwa pengalaman bekerja tidak berpengaruh pada produktivitas tenaga kerja panen kelapa sawit. Menurut Manulang 1984 pengalaman kerja adalah pembentukan pengetahuan atau ketrampilan tentang metode suatu pekerjaan karena keterlibatan karyawan tersebut dalam

Tabel 2. Uji F

\begin{tabular}{|c|c|c|c|c|c|c|}
\hline \multicolumn{7}{|c|}{ ANOVA $^{b}$} \\
\hline & \multirow{2}{*}{$\begin{array}{c}\begin{array}{c}\text { Sum of } \\
\text { Squares }\end{array} \\
168.411\end{array}$} & \multirow{2}{*}{$\begin{array}{r}\text { Df } \\
4\end{array}$} & $\begin{array}{c}\text { Mean } \\
\text { Square }\end{array}$ & \multirow{2}{*}{$\begin{array}{c}\mathrm{F} \\
18.521\end{array}$} & \multirow{2}{*}{$\begin{array}{l}\text { Sig. } \\
.000^{\mathrm{a}}\end{array}$} \\
\hline \multirow[t]{3}{*}{1} & \multirow{3}{*}{$\begin{array}{l}\text { n } \\
\text { Residual } \\
\text { Total }\end{array}$} & & & 42.103 & & \\
\hline & & 272.789 & 120 & 2.273 & & \\
\hline & & 441.200 & 124 & & & \\
\hline
\end{tabular}

a. Predictors: (Constant), Pengalaman Bekerja, Usia, Premi, Jumlah

Tanggungan

b. Dependent Variable: Produktivitas

Untuk menentukan Uji F dari tabel 9 maka dengan ketentuan dengan membandingkan nila F Hitung (F) dan F Tabel (sig), ketentuannya yaitu :

1. jika $\mathrm{F}$ hitung $\geq \mathrm{F}$ tabel berarti $\mathrm{h}_{0}$ ditolak, artinya secara simultan variable independen (premi, usia, jumlah tanggungan, pengalaman bekerja) mempengaruhi variable dependen (Produktivitas).

2. jika $\mathrm{F}$ hitung $<\mathrm{F}$ tabel berarti $\mathrm{h}_{0}$ diterima, artinya secara simultan variable independen (premi, usia, jumlah tanggungan, pengalaman bekerja) tidak mempengaruhi Variabel dependen (Produktivitas) (Sudjana, 2005)

Pada penelitian ini dapat diketahui pelaksanaan tugas pekerjaan. Namun dikarenakan Pengalaman kerja yang dimiliki belum tentu bisa mengurangi kesalahan-kesalahan yang dilakukan saat bekerja, juga pengalaman seseorang biasanya sulit untuk menerima inovasi dan sesuatu yang baru karena lebih berpedoman pada pengalaman kerja yang lama jadi dalam penelitian ini pengalaman bekerja tidak mempengaruhi tingkat produktivitas. 


\section{KESIMPULAN DAN SARAN Kesimpulan}

Berdasarkan hasil analisis dan pembahasan, maka ditarik kesimpulan sebagi berikut :

1. Tingkat Produktivitas tenaga kerja panen kelapa sawit di PT. Perkebunan Nusantara VI Unit Usaha Rimbo Satu Kecamatan Rimbo Bujang Kabupaten Tebo tinggi.

2. Secara parsial faktor premi dan faktor jumlah tanggungan memberikan pengaruh nyata terhadap produktivitas tenaga kerja panen kelapa sawit, hal ini dapat dilihat pada nilai $\mathrm{t}$ hitung premi $7.562>\mathrm{t}$ tabel 0,000 dan $\mathrm{t}$ hitung jumlah tanggungan $2.532>\mathrm{t}$ tabel 0,013. Sedangkan untuk faktor usia dan faktor pengalaman bekerja tidak berpengaruh secara nyata terhadap produktivitas tenaga kerja panen kelapa sawit di PT. Perkebunan Nusantara VI Unit Usaha Rimbo Satu Kecamatan Rimbo Bujang Kabupaten Tebo.

\section{Saran}

1. Untuk perusahaan disarankan agar perlu memberikan tambahan yang sesuai kepada pemanen kelapa sawit sehingga pemanen dapat termotivasi untuk tetap terampil dan giat dalam melakukan pekerjaan, sehingga produktivitas meningkat dan begitu juga untuk pengasilan pemanen.

2. Diperlukan dilakukan penelitian lebih lanjut untuk mengetahui faktor-faktor lain apa saja yang dapat mempengaruhi produktivitas tenaga kerja panen seperti : Jaminan Sosial, Gizi dan kesehatan, atau faktor-faktor lainnya.

\section{DAFTAR PUSTAKA}

Hernanto, 1989. Ilmu Usaha Tani. Penebar Swadaya. Jakarta.
Kaswan, 2012. Manajemen Sumber Daya Manusia Untuk Keunggulan Bersaing Organisasi. Graha ilmu. Yogyakarta

Sihotang, 2007. Manajemen Sumber Daya Manusia. PT. Pradnya Paramitha. Jakarta.

Sudjana, 2005. Metode Statistika Edisi Ke6. Tarsito. Jakarta.

Sugiyono, 2012. Metode Penelitian. Alfabeta. Bandung.

Sugiyono, 2017. Metode Penelitian Kuantitatif, Kualitatif dan R\&D. Alfabeta. Bandung.

Sumarsono, 2009. Ekonomi Sumber Daya Manusia Teori dan Kebijakan Publik. Graha Ilmu. Yogyakarta. 